\title{
ALGUNS SABERES DOCENTES ADQUIRIDOS EM UMA DISCUSSÃO SOBRE A MEDIÇÃO DE PROFUNDIDADE COM O BÁCULO DE PETRUS RAMUS
}

\section{SOME TEACHING KNOWLEDGES MOBILIZED DURING A DISCUSSION ABOUT DEPTH MEASUREMENT WITH THE BACULUM OF PETRUS RAMUS}

\author{
Francisco Hemerson Brito da Silva ${ }^{1}$; Ana Carolina Costa Pereira ${ }^{2}$, Antonia \\ Naiara de Sousa Batista ${ }^{3}$
}

\begin{abstract}
RESUMO
O professor de Matemática, ao longo de seu ofício, necessita estar sempre se atualizando em relação a outros tipos de conhecimentos existentes, de forma a adquiri-los para algum auxílio em sala de aula. Um dos motivos, para isso, deve-se à exigência das instituições educacionais, requisitando, cada vez mais, profissionais qualificados e aptos a ensinar. Alguns desses saberes podem ser obtidos e mobilizados na universidade, em particular, a partir de vivências práticas, por meio de atividades extracurriculares. Nesse sentido, nosso intuito é relacionar alguns saberes docentes com os conhecimentos obtidos por professores em formação inicial, em um minicurso de extensão universitária, que explorou o procedimento de medição de profundidade com o báculo de Petrus Ramus, sob a perspectiva da historiografia atualizada. Tal abordagem teve um alicerce na interface entre história e ensino de Matemática, que nos orientou no tratamento didático de um documento histórico para a elaboração do minicurso. Assim, nossa experiência se configura como um estudo aplicado com caráter qualitativo-descritivo, que, por meio do levantamento de um questionário eletrônico, permitiu-nos ter uma noção acerca das contribuições do curso para os participantes. À vista disso, foram elencadas, pelos cursistas, algumas concepções sobre os conhecimentos que não se tinha antes da vivência, mas que foram adquiridos depois. Entre eles, os saberes relacionados à prática docente, relevantes para a formação de professores. Dessa forma, podemos concluir, com a experiência do minicurso, que a situação de medição pode articular múltiplos saberes de ordem prática, matemática, epistemológica, tornando o processo de ensino e aprendizagem mais integrado aos docentes.
\end{abstract}

Palavras-chave: Formação inicial do professor de Matemática; Prática docente; Vivência universitária; Báculo de Petrus Ramus.

\footnotetext{
${ }^{1}$ Graduando de Licenciatura em Matemática na Universidade Estadual do Ceará (UECE). Bolsista de Iniciação Científica e Tecnológica da Universidade Estadual do Ceará (UECE), Fortaleza, Ceará, Brasil. Endereço para correspondência: Av. Silas Munguba, 1700, Itaperi, Fortaleza, Ceará, Brasil, CEP: 60.740903. E-mail: francisco.hemerson@ aluno.uece.br.

ORCID iD: http://orcid.org/0000-0003-3642-6006.

${ }^{2}$ Pós-Doutora em Educação Matemática pela Pontifícia Universidade Católica de São Paulo (PUC-SP). Docente do programa de Pós-Graduação em Educação e do curso de Licenciatura em Matemática da Universidade Estadual do Ceará (UECE), Fortaleza, Ceará, Brasil. Endereço para correspondência: Av. Silas Munguba, 1700, Itaperi, Fortaleza, Ceará, Brasil, CEP: 60.740-903. E-mail: carolina.pereira@uece.br.

ORCID iD: http://orcid.org/0000-0002-3819-2381.

${ }^{3}$ Doutoranda em Educação pela Universidade Estadual do Ceará (UECE). Docente do curso de Licenciatura em Matemática da Universidade Estadual do Ceará (UECE), Fortaleza, Ceará, Brasil. Endereço para correspondência: Av. Silas Munguba, 1700, Itaperi, Fortaleza, Ceará, Brasil, CEP: 60.740-903. E-mail: naiara.batista@uece.br.
}

(iD) ORCID iD: http://orcid.org/0000-0003-2305-7088. 
Francisco Hemerson Brito da Silva, Ana Carolina Costa Pereira e Antonia Naiara de Sousa Batista Alguns saberes docentes adquiridos em uma discussão sobre a medição de profundidade com o báculo de Petrus Ramus

ABSTRACT
During his profession, the math's teacher needs to be always updating himself on other kinds of existent knowledges, in order to acquire them for some assistance in classroom. One of the reasons for this is due to a demand from educational institutions, requiring even more qualified and ready to teach professionals. Some of this knowledge can be obtained and mobilized at the university, in particular, from practical experiences through extracurricular activities. In this sense, our aim is to relate some teaching knowledge to the knowledge acquired by teachers in initial training, in a university extension minicourse that explored the depth measurement procedure with the Baculum of Petrus Ramus under an updated historiography perspective. Such approach had a foundation in the interface between history and mathematics teaching, which guided us in the didactic treatment of a historical document for the elaboration of the minicourse. Thus, our experience is configured as an applied study with a qualitative-descriptive character, which through the survey of an electronic questionnaire, allowed us to have a notion about the contributions of the course to the participants. Therefore, the participants listed some conceptions about the knowledge that they didn't had before the experience, but were acquired afterwards. Among them, the knowledge related to teaching practice, relevant to teaching training. In this way, we can conclude on the experience of the minicourse, that the measurement situation can articulate multiple practical, mathematical and epistemological knowledges, making the teaching and learning process more integrated to the teachers.

Keywords: Math's teacher initial training; Teaching practice; University experience, Baculum of Petrus Ramus. 


\section{Introdução}

A demanda por profissionais mais qualificados é uma exigência que vem sendo feita há um certo tempo pelo mercado de trabalho. No magistério não é diferente, uma vez que as instituições, em esferas municipais e estaduais, buscam por professores que estejam aptos a exercerem seus ofícios, articulando os saberes aprendidos ao longo de sua formação. Nisso, a universidade tem um papel relevante ao prover de conhecimentos curriculares e didáticos os futuros docentes, bem como preparando-os para o cotidiano vivido nas escolas da Educação Básica.

Ademais, o professor em formação inicial necessita ter interesse no que vai ensinar, de modo que consiga planejar e desenvolver novas metodologias de ensino em determinado conteúdo. Em particular, para ensinar Matemática, o docente precisa do domínio de alguns saberes que podem contribuir com suas práticas didáticas em sala de aula, tornando esse ambiente um lugar "onde os alunos tenham plena liberdade de se expressar, criar, desenvolver seu raciocínio e sua originalidade, de descobrir por eles mesmos caminhos diferentes de chegar às respostas" (CRESCENTI, 2008, p. 85).

Com isso, temos que saberes ligados às práticas pedagógicas de ensino, vivências e conhecimentos curriculares são importantes na formação inicial do professor de Matemática. Além disso, o docente deve estar atento a algumas atualizações em relação a tais saberes, de forma que busque complementar a estrutura curricular estudada na universidade com meios alternativos, diversificando o seu processo de formação.

Uma das formas de implementar os conceitos obtidos pelos licenciandos é por meio de atividades extracurriculares, que "podem contribuir para o desenvolvimento desses estudantes durante o curso de graduação e para o alcance dos seus objetivos profissionais" (PEREIRA et al., 2011, p. 164). Dentro dessas atividades, encontramos os minicursos de extensão universitária, sendo cursos com uma carga horária bem reduzida, com abordagens mais curtas e direcionadas.

Nesse sentido, ministramos um minicurso voltado para a formação inicial dos licenciandos em Matemática, dentro da XXV Semana Universitária ${ }^{4}$, promovida pela Universidade Estadual do Ceará (UECE), em novembro de 2020. O minicurso se propôs a discutir os conhecimentos matemáticos incorporados em uma situação de medição de

\footnotetext{
${ }^{4}$ Para mais informações, consultar o link: https://semanauniversitaria2020.uece.br.
} 
Francisco Hemerson Brito da Silva, Ana Carolina Costa Pereira e Antonia Naiara de Sousa Batista Alguns saberes docentes adquiridos em uma discussão sobre a medição de profundidade com o báculo de Petrus Ramus

altura com o báculo ${ }^{5}$ de Petrus Ramus, especificadamente, uma forma de medir a profundidade de um poço no século XVI.

Para isso, a nossa proposta foi alicerçada na interface entre história e ensino de Matemática, que possibilita a criação de metodologias didáticas voltadas para o ensino de Matemática. Entre os recursos provenientes da história da Matemática, encontramos os tratados antigos e os instrumentos matemáticos, que servem de base para a idealização de tal articulação.

Ao adentrar na interface, é possível iniciar um diálogo entre o historiador e o educador matemático, por meio da escolha de "um documento histórico, que pode ser um texto ou excerto de um texto, ou ainda um instrumento, um monumento, uma foto, uma imagem, uma figura, um vídeo, entre muitos outros" (PEREIRA; SAITO, 2019, p. 346). Posteriormente, é selecionada uma parte específica do objeto de pesquisa, para se fazer um estudo em relação a aspectos de ordem contextual, histórica, epistemológica e matemática, com vistas a entender como eles se relacionam. Em seguida, partimos para a identificação de elementos potencialmente didáticos, que podem ser voltados para o ensino e, assim, elaboramos as atividades para contemplar esse feito, visando aplicá-las em algum público e validar os resultados obtidos com elas.

À vista disso, no nosso caso, temos que o documento histórico escolhido foi o Via regia ad geometriam, que fez parte de uma rica literatura envolvendo a geometria prática dos séculos XVI e XVII. O tratado foi escrito por Petrus Ramus ${ }^{6}(1515-1572)$ e tinha o intuito de colocar as matemáticas ${ }^{7}$ do período em seu devido caminho, frisando a gama de aplicações que elas poderiam ter no contexto da agrimensura (SILVA; PEREIRA, 2020c). O texto também traz, em seu escopo, conhecimentos geométricos em relação à Geometria Plana e à Geometria Espacial, uma vez que, para Ramus, a Geometria é feita para medir objetos.

Dentro do tratado, está inserido o instrumento báculo, que servia para medir distâncias terrestres, como comprimento, altura e largura, sendo um grande auxílio para diversas profissões da antiguidade clássica, como arquitetos, engenheiros, entre outros

\footnotetext{
${ }^{5}$ É um instrumento antigo de medição, muito utilizado por agrimensores e outras profissões dos séculos XVI e XVII. Para mais informações, consultar Pereira e Saito (2019).

${ }^{6}$ Para mais informações sobre o autor do documento, vide Silva e Pereira (2020c).

${ }^{7}$ As matemáticas citadas são referentes às disciplinas do quadrivium: geometria, aritmética, astronomia e música, que, até meados do século XVIII, ainda não tinham se tornado um campo de conhecimentos como temos hoje (SAITO, 2015).
} 
Francisco Hemerson Brito da Silva, Ana Carolina Costa Pereira e Antonia Naiara de Sousa Batista Alguns saberes docentes adquiridos em uma discussão sobre a medição de profundidade com o báculo de Petrus Ramus

(SILVA, PEREIRA, 2020b). Além de procedimentos manuais, junto ao seu posicionamento, o báculo utiliza alguns conhecimentos matemáticos para a validação do que se quer medir, entre esses, indicamos o uso de semelhanças de triângulos, junto à razão e proporção.

Segundo Silva e Pereira (2020a), a partir do manuseio do instrumento, Ramus define algumas situações particulares para a medição de objetos definidos, que podem ajudar o usuário a simplificar o processo de mensuração. No entanto, detemo-nos a explorar uma única situação, voltada para a medição de um tipo de altura, sendo esta a profundidade. Com isso, fizemos a elaboração de atividades referentes à medição indicada, para serem aplicadas no minicurso de extensão universitária.

Assim, indicamos que, ao desenvolver um estudo com um tipo de fonte histórica, vimos a possibilidade de proporcionar ao docente em formação o aprendizado de variados saberes relevantes à sua prática docente. Com isso, a aquisição de tais conceitos podem causar uma reflexão no professor, a respeito do alcance de suas metodologias de ensino, culminando na construção do conhecimento de seu aluno.

Dessa forma, visamos relacionar alguns dos saberes docentes conhecidos com os que foram adquiridos, em nosso minicurso de extensão, pelos docentes em formação inicial da UECE. Para tal, organizamos nosso escrito em quatro seções, com a descrição do caminho metodológico percorrido, algumas informações específicas do minicurso e uma parte dos resultados obtidos com ele, fazendo o fechamento com nossas considerações e agradecimentos.

\section{O percurso metodológico}

A trajetória desenvolvida, ao longo de nossa vivência, foi dividida em quatro etapas, que culminaram na organização deste relato de experiência. A primeira delas esteve relacionada com a construção do aporte teórico do estudo, enquanto a segunda parte se deteve em planejar o minicurso, fazendo a divisão conteudista em reuniões, estas acontecendo por meio de videoconferências. No terceiro momento, tivemos a execução do minicurso de extensão para os alunos da UECE, com vistas a compartilhar saberes de nossas investigações, bem como recolher dados, que foram tratados, na última fase, como resultados obtidos. 
Francisco Hemerson Brito da Silva, Ana Carolina Costa Pereira e Antonia Naiara de Sousa Batista Alguns saberes docentes adquiridos em uma discussão sobre a medição de profundidade com o báculo de Petrus Ramus

As ações que foram desenvolvidas se deram a partir do projeto integrado de pesquisa e extensão, intitulado de projeto guarda-chuva ${ }^{8}$, que visa "promover uma investigação de certos artefatos antigos, de modo a direcioná-los para estratégias de ensino e a elaboração de atividades que possam contribuir para construção de conhecimentos matemáticos" (SILVA; PEREIRA; BATISTA, 2020, p. 95). O projeto ainda conta com contribuições de licenciandos em Matemática da UECE, mestrandos e doutorandos na área de Educação da UECE e de outras instituições de Ensino Superior, que atuam ativamente dentro do Grupo de Pesquisa em Educação e História da Matemática (GPEHM) ${ }^{9}$.

À vista disso, muitas discussões são feitas no GPEHM acerca do estudo com instrumentos matemáticos, com o propósito de delinear propostas de mobilização de algumas atividades que incorporam o conhecimento matemático presente em tais instrumentos. Para o início dessa articulação, é preciso a construção de um aporte teórico que parta da escolha de uma fonte documental primária, que, em nosso caso, é o tratado Via regia ad geometriam (SILVA; PEREIRA, 2020b).

Assim, nosso referencial se pautou nas descrições de uma situação de medição contida no tratado Via regia ad geometriam, definida por Ramus como a segunda forma de medir alturas. Tal situação incorpora conhecimentos matemáticos, como mostra a pesquisa de Silva e Pereira (2020b) e, com isso, vimos a possibilidade da criação de atividades que contemplassem esses conceitos, baseados nas orientações da interface entre história e ensino de Matemática. Para isso, requisitamos o estudo de Pereira e Saito (2019) como fonte de consulta, dando atenção ao processo de construção da interface.

Para conhecermos acerca dos saberes docentes, que são adquiridos pelos professores antes, durante e após sua formação profissional, embasamo-nos nas orientações dadas por Tardif e Raymond (2000), junto às de Crescenti (2008), sendo muito úteis em nosso estudo. Enquanto as conceituações de Prodanov e Freitas (2013) nos ajudaram a entender melhor os tipos de pesquisas existentes e os instrumentos de coletas adequados a cada uma delas, selecionando, portanto, as mais apropriadas, que se encaixaram em nossa proposta.

\footnotetext{
${ }^{8} \mathrm{O}$ projeto tem por título: A construção de interfaces entre história e ensino da matemática por meio de antigos instrumentos matemáticos para a elaboração de uma proposta didático-pedagógica e foi aceito no conselho de ética da UECE, sob o protocolo de parecer, com número 3.285.665.

${ }^{9}$ É um grupo de pesquisa, associado à Universidade Estadual do Ceará. Para saber mais informações, acesse o blog: http://gpehm.blogspot.com.
} 
Francisco Hemerson Brito da Silva, Ana Carolina Costa Pereira e Antonia Naiara de Sousa Batista Alguns saberes docentes adquiridos em uma discussão sobre a medição de profundidade com o báculo de Petrus Ramus

Com o referencial trazido, foi possível começarmos o planejamento do minicurso, passando a escolher os seus conteúdos e a dividi-los em módulos, bem como traçar os objetivos relacionados aos participantes, como também ao ministrante. Além disso, organizamos as atividades a serem desenvolvidas para cada unidade temática, de maneira que elas pudessem contemplar as metas traçadas na realização do minicurso. Assim sendo, a ministração do minicurso ocorreu à distância, por meio da plataforma on-line de videoconferência, sendo esta o Google Meet e teve um ministrante, uma tutora e uma coordenadora à frente da organização.

A respeito da quantidade de vagas do minicurso, este foi ofertado para 30 pessoas e visando atender a essa demanda, alguns treinamentos foram feitos, pelo grupo gestor da UECE, para o uso de instrumentos tecnológicos, sendo um deles: como utilizar o Google Meet na criação de salas virtuais. Ainda recebemos o apoio da Pró-Reitoria de PósGraduação e Pesquisa (PROPGPq), dando-nos a orientação de como organizar o minicurso; da Fundação Cearense de Apoio ao Desenvolvimento Científico e Tecnológico (FUNCAP) ${ }^{10}$, que entrou com o financiamento de bolsistas e do GPEHM, com os aportes teóricos e discursivos da experiência.

A metodologia de aulas utilizada, para o desenvolvimento do minicurso, foi a expositiva-dialogada, que é tida como "uma estratégia em que o professor expõe o conteúdo, mas com participação ativa dos estudantes” (SÁ et al., 2017, p. 631). Nesse sentido, com as sessões de videoconferência, foi-nos permitido debater e explorar as questões de ordem prática, contextual, epistemológica e matemática, relacionadas à construção, ao uso do báculo e, em particular, à situação de medição de profundidade.

Dessa forma, ao recolhermos as atividades que foram disponibilizadas aos cursistas, visualizamos alguns dados para a pesquisa e usamos métodos comumente mobilizados na comunidade científica. Tal processo nos direcionou para o entendimento do uso dessas técnicas nos dados adquiridos, fazendo com que interligássemos a validação de algumas hipóteses inferidas antes da realização do minicurso, com tais conceitos apresentados posteriormente.

Com isso, nosso estudo é tido como uma pesquisa aplicada em relação à sua natureza, uma vez que, a partir da problemática específica, gerou conhecimentos direcionados à solução da mesma (PRODANOV; FREITAS, 2013). Quanto à abordagem,

${ }^{10}$ Para saber mais informações, segue o link: https://www.funcap.ce.gov.br. 
Francisco Hemerson Brito da Silva, Ana Carolina Costa Pereira e Antonia Naiara de Sousa Batista Alguns saberes docentes adquiridos em uma discussão sobre a medição de profundidade com o báculo de Petrus Ramus

primamos por utilizar a qualitativa, visto que o "ambiente natural é a fonte direta para coleta de dados e o pesquisador é o instrumento-chave" (PRODANOV; FREITAS, 2013, p.70), que, no nosso caso, é o próprio minicurso de extensão universitária. Ademais, segundo Prodanov e Freitas (2013), com esse tipo de pesquisa, é permitido fazer o uso da interpretação, bem como da atribuição de significados a objetos recorrentes.

Nessa perspectiva, Prodanov e Freitas (2013) ressaltam que a pesquisa qualitativa é também descritiva, já que os pesquisadores podem analisar os dados obtidos indutivamente. Assim, usamos a pesquisa descritiva para contemplar o objetivo do estudo, pois são feitas, pelo pesquisador, algumas observações com registro e descrição, sem a sua interferência direta. Para tanto, utilizam-se técnicas para a coleta de dados, tais como a "entrevista, o formulário, o questionário, o teste e a observação" (PRODANOV; FREITAS, 2013, p. 52).

Diante disso, para fazermos o uso da pesquisa descritiva, familiarizamo-nos com algumas técnicas específicas, em particular, o levantamento de um formulário entregue no final do minicurso. Esse procedimento metodológico "ocorre quando envolve a interrogação direta das pessoas cujo comportamento desejamos conhecer através de algum tipo de questionário" (PRODANOV; FREITAS, 2013, p. 57), que, em nossa vivência, foi em relação a saber quais conhecimentos os cursistas puderam obter no minicurso.

À vista de tudo o que foi descrito, indicamos que o percurso metodológico traçado foi sustentado para que a pesquisa seguisse em um caminho organizado, de forma que complementasse o que propomos a fazer. Alegamos, ainda, que as fontes de pesquisa utilizadas para o embasamento têm sua relevância nas pesquisas acadêmicas, uma vez que deram grandes contribuições a diversas modalidades no ensino.

\section{O minicurso de extensão universitária}

O minicurso intitulado: os conhecimentos matemáticos presentes na medição de profundidade com o báculo de Petrus Ramus foi ministrado de maneira remota entre os dias 24, 25 e 26 de novembro de 2020, devido à pandemia da COVID-19 ${ }^{11}$ em que estamos. Tal vivência foi promovida dentro da XXV Semana Universitária da UECE,

\footnotetext{
${ }^{11}$ Referente ao novo Coronavírus, que está envolvendo a população global em um grande colapso.
} 
Francisco Hemerson Brito da Silva, Ana Carolina Costa Pereira e Antonia Naiara de Sousa Batista Alguns saberes docentes adquiridos em uma discussão sobre a medição de profundidade com o báculo de Petrus Ramus

com uma curta carga horária de seis horas, direcionada para todos os alunos da instituição, em especial, os licenciandos em Matemática.

Com o intuito de discutir alguns entes matemáticos, que emergem do uso do báculo, o minicurso deu atenção para o estudo das orientações dadas por Petrus Ramus para medir a altura reversa ${ }^{12}$ de um poço, utilizando seu instrumento. Essa denominação de altura é o que temos hoje como profundidade, que foi descrita em uma situação de medição encontrada no tratado: Via regia ad geometriam.

Logo, a estrutura conteudista do minicurso partiu de considerações historiográficas atualizadas, que nos concederam algumas noções para explorar os artifícios da história da Matemática com outros aspectos. Assim, o minicurso foi dividido em três momentos, contando com objetos de exploração bem definidos, de forma que um fosse subsequente ao outro, sendo organizados no quadro abaixo.

Quadro 1 - Síntese da organização conteudista do minicurso.

\begin{tabular}{|c|c|c|c|}
\hline $\begin{array}{l}\text { Unidades } \\
\text { temáticas }\end{array}$ & Objetivos para os discentes & Objetivos dos docentes & $\begin{array}{c}\text { Atividades } \\
\text { desenvolvidas }\end{array}$ \\
\hline \multirow{3}{*}{$\begin{array}{l}\text { MÓDULO 1: } \\
\text { Petrus Ramus e o } \\
\text { documento Via } \\
\text { regia ad } \\
\text { geometriam (1636) }\end{array}$} & $\begin{array}{l}\text { Compreender a importância } \\
\text { de Petrus Ramus para a } \\
\text { matemática dos séculos XVI } \\
\text { e XVII. }\end{array}$ & \multirow{3}{*}{$\begin{array}{c}\text { Apresentar aos } \\
\text { participantes o documento } \\
\text { que será estudado, assim } \\
\text { como seu autor e sua } \\
\text { importância para a } \\
\text { disseminação da geometria } \\
\text { prática dos séculos XVI e } \\
\text { XVII. }\end{array}$} & \multirow[t]{2}{*}{ Videoconferência } \\
\hline & Reconhecer a obra Via regia & & \\
\hline & $\begin{array}{l}\text { ad geometriam }(1569)^{13} \\
\text { como parte integrante do } \\
\text { diálogo entre as geometrias } \\
\text { teórica e prática nos séculos } \\
\text { XVI e XVII. }\end{array}$ & & Questionário \\
\hline \multirow{2}{*}{$\begin{array}{l}\text { MÓDULO 2: } \\
\text { Conhecendo o } \\
\text { báculo de Petrus } \\
\text { Ramus }\end{array}$} & \multirow{2}{*}{$\begin{array}{c}\text { Conhecer o báculo de Petrus } \\
\text { Ramus a partir da descrição } \\
\text { de suas partes contidas no } \\
\text { Via regia ad geometriam - } \\
\text { The Way To Geometry } \\
\text { (1636). }\end{array}$} & \multirow{2}{*}{$\begin{array}{l}\text { Fazer com que os } \\
\text { participantes conheçam e } \\
\text { visualizem o báculo de } \\
\text { Petrus Ramus, a partir de } \\
\text { uma situação problema. }\end{array}$} & Videoconferência \\
\hline & & & Relatório \\
\hline \multirow{2}{*}{$\begin{array}{c}\text { MÓDULO 3: } \\
\text { Estudo da } \\
\text { medição de } \\
\text { profundidade com } \\
\text { o báculo }\end{array}$} & \multirow{2}{*}{$\begin{array}{c}\text { Explorar a situação de } \\
\text { medição de modo a } \\
\text { identificar a matemática nela } \\
\text { presente. }\end{array}$} & \multirow{2}{*}{$\begin{array}{l}\text { Estimular os participantes } \\
\text { a explorarem, formularem } \\
\text { e expressarem os } \\
\text { conhecimentos } \\
\text { matemáticos mobilizados } \\
\text { no manuseio do báculo, } \\
\text { questionando o processo } \\
\text { de medição e justificando } \\
\text { seus passos. } \\
\end{array}$} & Videoconferência \\
\hline & & & Relatório \\
\hline
\end{tabular}

\footnotetext{
12 Para entender melhor acerca dessa denominação, vide Silva e Pereira (2020b).

${ }^{13}$ Referente à primeira versão do documento Via regia ad geometriam, intitulado por Arithmeticae libri duo: geometriae septem et viginti (SILVA; PEREIRA, 2020c).
} 
Francisco Hemerson Brito da Silva, Ana Carolina Costa Pereira e Antonia Naiara de Sousa Batista Alguns saberes docentes adquiridos em uma discussão sobre a medição de profundidade com o báculo de Petrus Ramus

\begin{tabular}{|l|c|c|c|}
\hline & $\begin{array}{c}\text { Compreender uma aplicação } \\
\text { do báculo a partir das } \\
\text { instruções fornecidas por } \\
\text { Petrus Ramus. }\end{array}$ & $\begin{array}{c}\text { Elencar as possíveis } \\
\text { potencialidades didáticas } \\
\text { que envolve a situação de } \\
\text { uso do báculo. }\end{array}$ & Questionário \\
\hline
\end{tabular}

Fonte: Elaborado pelos autores (2021).

Alegamos ainda que os módulos organizados, no Quadro 1, também tiveram base nos objetivos traçados tanto para os docentes do minicurso quanto para os cursistas. Tais propósitos seguiram em uma mesma vertente, com vistas a qualificar o objetivo geral da nossa vivência, que, junto a outras metodologias didáticas e aos instrumentos de coleta de dados, permitiu-nos validá-lo.

Assim, na primeira etapa, foi explorada a parte conceitual e epistemológica, com ênfase em Petrus Ramus e em seu documento em questão. Apresentamos fatores importantes da vida de Ramus, bem como as suas contribuições para a comunidade acadêmica de sua época, que perduram até os dias de hoje. Ademais, explicitamos a razão dele em publicar o seu documento, que tanto contribuiu para o diálogo da geometria prática e geometria teórica dos séculos XVI e XVII.

No segundo momento, detemo-nos em mostrar o processo de construção e uso do báculo, baseados nas instruções do excerto de Ramus. Destacamos, nesse período, as principais partes que compõem o instrumento, a funcionalidade de cada parte e a sua relevância na montagem, como no manejo dele. Ao final da aula, fizemos uma breve discussão com os alunos acerca dos conhecimentos matemáticos incorporados no momento de constituição e utilização do báculo, indicando a relevância deles para o processo.

Já na última etapa, a partir de tudo o que foi exposto e discutido nos módulos anteriores, direcionamos a nossa abordagem para o estudo de uma das dez situações de medição ${ }^{14}$, descrita por Ramus em seu tratado. A situação é referente a uma forma de medir altura específica com o báculo, sendo esta a profundidade de um poço. Como o nosso foco era voltado para tal procedimento, fizemos uma adaptação no texto do tratado para o português, pensando na compreensão dos alunos e, com isso, mediamos uma discussão mais direcionada, que teve um tempo maior em relação à última feita, obtendo alguns resultados.

\footnotetext{
${ }^{14}$ Para conhecer melhor esse aspecto, vide Silva e Pereira (2020a).
} 
Francisco Hemerson Brito da Silva, Ana Carolina Costa Pereira e Antonia Naiara de Sousa Batista Alguns saberes docentes adquiridos em uma discussão sobre a medição de profundidade com o báculo de Petrus Ramus

Conforme é destacado no Quadro 1, fizemos o uso de algumas atividades que serviram como material de coleta para a atividade de extensão, estabelecendo, assim, um acordo com os cursistas a partir do Termo de Concessão de Imagem e Som (TCIS), para fazer o uso das gravações com as discussões e anotações no chat. Dessa maneira, ao longo do minicurso, desenvolvemos: as videoconferências, como uma forma de manter um contato direto com os discentes; os relatórios, que serviram como meio articulador dos debates e, por último, os questionários realizados de maneira on-line, com perguntas direcionadas para cada etapa.

Entre os 30 participantes do minicurso, apenas 22 deles foram aprovados, comparecendo nos três dias da realização do evento e na entrega das atividades. Observamos que a maioria dos alunos graduandos já haviam cursado a disciplina de História da Matemática na universidade, sendo este um fator citado por muitos para a participação no minicurso. Quanto à atuação na Educação Básica, muitos dos cursistas ainda não ensinam de maneira presente em tal instância do ensino, o que faz todo o sentido, pois alguns alunos preferem se qualificar antes para exercer o ofício depois.

Por fim, concluímos que o minicurso ficou bem moldurado em virtude da carga horária definida, dos conteúdos apresentados e da condução dos organizadores. Apesar de termos tido um tempo reduzido para seu desenvolvimento, procuramos propor atividades e vivências relevantes para os professores em formação, elucidando a importância de se fazer a relação do saber teórico com o saber prático.

\section{Os conhecimentos adquiridos no minicurso e sua relação com os saberes docentes}

Ao longo de sua formação profissional, o professor de Matemática necessita da obtenção de conhecimentos que o ajudem em seu ofício, de forma que fique apto a lidar com todo tipo de situação em sala de aula. Alguns desses saberes já são amadurecidos pelos docentes antes da formação inicial, enquanto alunos da Educação Básica, quando começam a construir suas primeiras concepções éticas, julgando como bom professor aquele que sabe ensinar e tem a didática adequada (TARDIF; RAYMON, 2000).

Assim, é relevante que o professor em formação esteja buscando abordagens alternativas para o ensino de Matemática, visando tornar o aluno um ser mais ativo na construção de seu próprio conhecimento. Para isso, o licenciando, ainda na graduação, deve se apropriar não só do conteúdo matemático, mas também de como fazer sua mobilização, recorrendo a algumas metodologias práticas. 
Francisco Hemerson Brito da Silva, Ana Carolina Costa Pereira e Antonia Naiara de Sousa Batista Alguns saberes docentes adquiridos em uma discussão sobre a medição de profundidade com o báculo de Petrus Ramus

A esse respeito, como uma forma de mapear as atribuições que os professores de Matemática obtêm ao final de sua formação inicial, Crescenti (2008) destaca alguns saberes docentes essenciais que compõem o saber-fazer em sala de aula, com a experiência. Em um deles, a autora dá ênfase para os saberes práticos "que constituem 'o conjunto de saberes atualizados, adquiridos e necessários no âmbito da prática da profissão docente e não provêm das instituições de formação nem dos currículos"” (CRESCENTI, 2008, p. 86). Além disso, Tardif e Raymond (2000) ressaltam que o saber prático pode desencadear novas atividades, bem como metodologias, aprimorando, portanto, os instrumentos de trabalho do docente.

Corroborando com isso, temos também os saberes pedagógicos que se relacionam diretamente com os saberes práticos, uma vez que os auxilia na colaboração entre a teoria e a prática (CRESCENTI, 2008). Segundo Tardif e Raymond (2000), os saberes indicados podem ser obtidos no momento de planejamento do professor, quando ocorre a busca por ferramentas que o auxiliem na mobilização do conteúdo que vai ser abordado na sala de aula. Ademais, o docente integra o saber pedagógico em sua socialização com os alunos, ao desenvolver o que foi planejado.

Desse modo, Crescenti (2008) afirma que o professor se beneficia positivamente de seus saberes experienciais, a partir de uma alocação do conjunto de vivências que podem trazer muitas contribuições à sua formação, de maneira a torná-lo um ser reflexivo de suas ações. Esses saberes são adquiridos na prática do ofício do professor e na sala de aula, quando ele aplica uma atividade diferenciada ou na convivência com sua turma, entre outras experiências (TARDIF; RAYMON, 2000). O docente ainda pode internalizar seu saber experiencial na prática do seu trabalho, juntamente com a socialização profissional com outros professores que atuam em seu campo de ensino.

Contudo, Crescenti (2008) indica, além disso, que o professor deve dominar os conteúdos e as práticas metodológicas de sua área, pois a falta de conhecimentos de ambas pode transformar o professor em um transmissor mecânico dos conhecimentos encontrados nos livros didáticos. Assim, é preciso que o docente solidifique seus saberes curriculares, tendo a confiança para a ministração de suas aulas, de forma que se aprofunde em cada assunto, a fim de separar as estratégias que serão usadas no mesmo (CRESCENTI, 2008). À vista disso, Tardif e Raymond (2000) ratificam que tais saberes podem ser obtidos em ambientes de formação de professores, como os estágios 
Francisco Hemerson Brito da Silva, Ana Carolina Costa Pereira e Antonia Naiara de Sousa Batista Alguns saberes docentes adquiridos em uma discussão sobre a medição de profundidade com o báculo de Petrus Ramus

supervisionados, cursos de reciclagem, entre outros. Para mais, o docente integra o saber curricular em sua socialização profissional, que, geralmente, ocorre em seu ambiente de trabalho.

À luz dos saberes apresentados anteriormente e sabendo que nosso minicurso de extensão proporcionou alguns conhecimentos para os participantes, procuramos organizá-los conforme a classificação de Crescenti (2008) e as definições de Tardif e Raymond (2000). Tais contribuições foram concebidas por um questionário feito ao final do minicurso, por meio de um formulário eletrônico, que foi disponibilizado aos cursistas.

O instrumento de coleta escolhido pode ser usado para a obtenção direta de informações com o pesquisado, a partir de algumas perguntas direcionadas sobre algum assunto específico. Prodanov e Freitas (2013, p. 111) ressaltam que o método "tem como vantagem permitir esclarecimento verbal adicional para as questões de entendimento mais difícil”, com vistas a delinear algumas respostas incompreensíveis. Com isso, a fim de compilar os retornos dados pelos discentes em uma questão norteadora, primamos por dispô-los progressivamente na tabela a seguir.

Quadro 2 - Os conhecimentos elencados e os saberes docentes.

\begin{tabular}{|c|c|c|}
\hline & $\begin{array}{l}\text { PERGUNTA: } \\
\text { O que você adquiriu de } \\
\text { conhecimentos que antes do } \\
\text { minicurso não conhecia? }\end{array}$ & $\begin{array}{c}\text { RESPOSTAS: FALAS DE ALGUNS } \\
\text { CURSISTAS }\end{array}$ \\
\hline Saber Prático & $\begin{array}{l}\text { A respeito da construção e uso } \\
\text { do báculo de Petrus Ramus }\end{array}$ & $\begin{array}{l}\text { Contextos anacrônicos de conteúdos matemáticos } \\
\text { e outras ideias de medição por meio do báculo } \\
\text { (PARTICIPANTE 13). }\end{array}$ \\
\hline $\begin{array}{c}\text { Saber } \\
\text { Pedagógico }\end{array}$ & $\begin{array}{l}\text { Para a humanização da } \\
\text { Matemática por meio da história } \\
\text { da Matemática }\end{array}$ & $\begin{array}{l}\text { Mostrar que através da História da Matemática } \\
\text { podemos mostrar para os alunos do Ensino } \\
\text { Fundamental e Médio que a matemática é } \\
\text { também humanizada que não envolve apenas } \\
\text { cálculos (PARTICIPANTE 7). }\end{array}$ \\
\hline \multirow[t]{2}{*}{$\begin{array}{c}\text { Saber } \\
\text { Experiencial }\end{array}$} & $\begin{array}{l}\text { Em relação ao contato inicial } \\
\text { com uma fonte histórica }\end{array}$ & $\begin{array}{l}\text { Foram vários conhecimentos adquiridos. Entrei } \\
\text { no curso por curiosidade, por não conhecer nada } \\
\text { sobre o Báculo e no final consegui entender o } \\
\text { contexto histórico em que o autor do instrumento } \\
\text { estava inserido, como o Báculo é construído e } \\
\text { como ele pode ser utilizado (PARTICIPANTE 9). }\end{array}$ \\
\hline & $\begin{array}{l}\text { Sobre interpretação textual e } \\
\text { visual }\end{array}$ & $\begin{array}{c}\text { Adquiri uma maneira ampla de tirar conceitos } \\
\text { matemáticos de determinada imagem. Ex.: } \\
\text { Imagem do poço (PARTICIPANTE 12). }\end{array}$ \\
\hline $\begin{array}{c}\text { Saberes } \\
\text { Curriculares }\end{array}$ & $\begin{array}{c}\text { Relativo à história da } \\
\text { Matemática e suas ramificações }\end{array}$ & $\begin{array}{l}\text { Um pouco de História da Matemática } \\
\text { (PARTICIPANTE 10). }\end{array}$ \\
\hline
\end{tabular}

Fonte: Elaborado pelos autores (2021).

A construção do Quadro 2 se deu através das respostas do formulário e das noções acerca de alguns saberes docentes. Com isso, indicamos que tivemos respostas variadas, 
Francisco Hemerson Brito da Silva, Ana Carolina Costa Pereira e Antonia Naiara de Sousa Batista Alguns saberes docentes adquiridos em uma discussão sobre a medição de profundidade com o báculo de Petrus Ramus

mas com certo padrão em relação aos eixos temáticos indicados e, assim, decidimos encaixar tais concepções de acordo com cada saber. Logo, no quadro, foi destacada uma fala dos cursistas para cada saber, a fim de complementar com o que foi especificado.

Dito isso, destacamos como saberes práticos aqueles referentes à construção e ao manuseio do báculo de Petrus Ramus, sobre o qual os cursistas puderam conhecer os condicionantes manipulativos por trás do instrumento, incluindo a Matemática presente nele, o material do período para sua constituição e a sua funcionalidade, já que, com o báculo, era possível medir distâncias, como comprimento, altura e largura.

Em outra perspectiva, um participante entendeu que, a partir de um tratamento didático com o báculo, o professor da Educação Básica, ao se apropriar de tal recurso, pode mostrar outra visão de conhecimentos. A concepção é referente à humanização da Matemática, com o uso da história da Matemática em sala de aula, que atribuímos como um saber pedagógico.

Como saber experiencial, organizamos as falas dos cursistas em relação a algumas vivências do minicurso, que, coincidentemente, reduziram-se a um único aspecto. Portanto, obtemos que, no geral, foi enfatizada a questão do contato preliminar com a fonte histórica, no nosso caso, o báculo. Os alunos ficaram surpresos ao encontrar muitos conceitos matemáticos incorporados no instrumento antigo, passando a mudar as suas convicções sobre ele.

Ainda em relação ao saber experiencial, também foi colocado que, na leitura do excerto de Petrus Ramus, houve uma forma diferente de interpretação, já que devemos entender as coisas do passado com a Matemática existente no período indicado. A respeito dos saberes curriculares, foi elencada a obtenção de conhecimentos relativos à história da Matemática e suas ramificações, pois alguns participantes não tinham ideia do quão vasto pode ser essa área e as pesquisas nela desenvolvidas.

Dessa forma, em razão da quantidade de saberes docentes adquiridos ao longo do minicurso, julgamos que a mobilização de tais conhecimentos pelo professor é bem positiva em sua formação. Além disso, leva o mesmo a tomar consciência de outras habilidades a serem desenvolvidas em seu ofício, de modo que construa uma identidade profissional com novas metodologias de ensino.

\section{Algumas considerações}


Francisco Hemerson Brito da Silva, Ana Carolina Costa Pereira e Antonia Naiara de Sousa Batista Alguns saberes docentes adquiridos em uma discussão sobre a medição de profundidade com o báculo de Petrus Ramus

Evidenciamos que o minicurso trouxe contribuições para os participantes, principalmente, em relação a buscar outras abordagens alternativas para o ensino de Matemática, implementando o método tradicional de dar aula. Com essas colaborações, esperamos ter acrescentado na formação dos futuros professores, de forma que eles possam construir seu perfil profissional.

Ademais, a vivência no curso proporcionou, aos cursistas, um contato longitudinal com uma fonte histórica, junto aos debates de como mobilizar tal recurso em sala de aula na Educação Básica. Esse fato abre possibilidades para que o ensino seja mais lúdico, uma vez que o docente pode fazer uma exploração que contemple alguns conhecimentos matemáticos, de modo a fazer uma relação entre a teoria e a prática.

Em outra perspectiva, enquanto docentes do minicurso, percebemos um amadurecimento de nossa parte a respeito do uso de novas metodologias, já que pudemos constatar o que deu certo e o que não deu. Com isso, buscaremos mudar nesses aspectos, sob a reflexão de melhorar o que não foi bom no minicurso e aprimorar o que deu certo na próxima prática didática desenvolvida.

A partir disso, julgamos que a interface entre história e ensino de Matemática, ainda, tem muito a oferecer aos professores de Matemática, visto que, além de diversificar o currículo de ensino, pode dispor, para eles, novas metodologias para seu ofício. Ao fazermos tal articulação, temos a mobilização de elementos de ordem matemática, epistemológica, histórica e contextual, que, aos poucos, estão vindo à tona e ganhando seu lugar na comunidade acadêmica.

Por fim, indicamos que este estudo buscou colaborar para a formação docente, bem como para a academia, posto que culminamos na exploração de novas estratégias que podem fazer toda a diferença em sala de aula. Ainda pretendemos avançar nesse meio, de forma que mais pesquisas a respeito dos instrumentos matemáticos e dos documentos históricos sejam desenvolvidas e amplamente divulgadas.

\section{Agradecimentos}

Gostaríamos de agradecer à UECE por todo o incentivo dado no decorrer da pesquisa, pelas formações que foram feitas para a utilização dos recursos digitais, possibilitando o contato com os cursistas por meio remoto. Saudamos também à PROPGPq, que lidou com a parte burocrática de lotação e oferta do minicurso para o público acadêmico, junto à FUNCAP, que tratou do financiamento necessário para a 
Francisco Hemerson Brito da Silva, Ana Carolina Costa Pereira e Antonia Naiara de Sousa Batista Alguns saberes docentes adquiridos em uma discussão sobre a medição de profundidade com o báculo de Petrus Ramus

realização do evento. Por fim, somos gratos ao GPEHM, por estar nos proporcionando ricas leituras, bem como debates que direcionam para o desenvolvimento de investigações como as que estamos realizando, de modo a contribuir para a prática docente.

\section{Referências}

CRESCENTI, Eliane Portalone. A formação inicial do professor de matemática: aprendizagem da Geometria e atuação docente. Praxis Educativa, Ponta Grossa (PR), v. 3, n. 1, p. 81-94, 21 jun. 2008. Disponível em: <https://www.researchgate.net/publication/272859377_A_formacao_inicial_do_profess or_de_Matematica_aprendizagem_da_Geometria_e_atuacao_docente>. Acesso em: 16 jan. 2021.

PRODANOV, Cleber Cristiano; FREITAS, Ernani César de. Metodologia do

Trabalho Científico: Métodos e Técnicas da Pesquisa e do Trabalho Acadêmico. 2. ed. Novo Hamburgo: Editora Feevale, 2013. 277 p. Disponível em:

$<$ https://www.feevale.br/institucional/editora-feevale/metodologia-do-trabalhocientifico---2-edicao >. Acesso em: 16 jan. 2021.

PEREIRA, Ana Carolina Costa; SAITO, Fumikazu. A reconstrução do Báculo de Petrus Ramus na interface entre história e ensino de matemática. Revista Cocar, Belém, v. 13, n. 25, pp. 342-372, 2019. Disponível em:

<https://periodicos.uepa.br/index.php/cocar/article/view/2164/1085>. Acesso em: 19 jan. 2021.

PEREIRA, Alessandra Knoll et al. A importância das atividades extracurriculares universitárias para o alcance dos objetivos profissionais dos alunos de administração da Universidade Federal de Santa Catarina. Revista Gestão Universitária na América Latina - GUAL, Florianópolis, Edição Especial, p. 163-194, 1 jun. 2011. Disponível em: <https://periodicos.ufsc.br/index.php/gual/article/view/19834535.2011v4nespp163/21969>. Acesso em: 21 jan. 2021.

SÁ, Eliane Ferreira de et al. As aulas de graduação em uma universidade pública federal: planejamento, estratégias didáticas e engajamento dos estudantes. Revista Brasileira de Educação, Rio de Janeiro, v. 22, n. 70, p. 625-650, jul. 2017. Disponível em: 〈https://www.scielo.br/pdf/rbedu/v22n70/1809-449X-rbedu-22-70-00625.pdf >. Acesso em: 18 jan. 2021.

SAITO, F. História da matemática e suas (re)construções contextuais. São Paulo: LF - Editorial, 2015. 259 p. (História da Matemática para Professores).

SILVA, Francisco Hemerson Brito da; PEREIRA, Ana Carolina Costa. Explorando as situações de medição de comprimento, altura e largura com o uso do báculo de Petrus Ramus. Revista Brasileira de História, Educação e Matemática - HIPÁTIA, São Paulo, v. 5, n.2, p. 398-409, dez. 2020a. Disponível em: <https://ojs.ifsp.edu.br/index.php/hipatia/article/view/1404/1102>. Acesso em: 18 jan. 2021. 
Francisco Hemerson Brito da Silva, Ana Carolina Costa Pereira e Antonia Naiara de Sousa Batista Alguns saberes docentes adquiridos em uma discussão sobre a medição de profundidade com o báculo de Petrus Ramus

SILVA, Francisco Hemerson Brito da; PEREIRA, Ana Carolina Costa. O báculo de Petrus Ramus e seu uso para medição de profundidade. Revista de Educação

Matemática - REMAT-Sp, São Paulo, v. 17, p. 1-14, 2 set. 2020b. Anual. Sociedade Brasileira de Educação Matemática. Disponível em:

〈https://www.revistasbemsp.com.br/REMat-SP/article/view/371/214>. Acesso em: 18 jan. 2021.

SILVA, Francisco Hemerson Brito da; PEREIRA, Ana Carolina Costa. O legado de Petrus Ramus e o tratado Via regia ad geometriam. Boletim Cearense de Educação e História da Matemática - BOCEHM, Fortaleza, v. 7, n. 20, p. 158-169, 11 jul. 2020c. Disponível em: 〈https://revistas.uece.br/index.php/BOCEHM/article/view/3297/3027>. Acesso em: 18 jan. 2021.

TARDIF, Maurice; RAYMOND, Danielle. Saberes, tempo e aprendizagem do trabalho no magistério. Educação e Sociedade, [S.I], v. 21, n. 72, p. 209-244, dez. 2000.

Disponível em: 〈https://www.scielo.br/pdf/es/v21n73/4214> . Acesso em: 01 fev. 2021.

Recebido em: 19 / 02 / 2021

Aprovado em: 14 / 04 / 2021 